\title{
4 Transformative paths, multi-scalarity of knowledge bases and Industry 4.0
}

\author{
Marco Bellandi, Cristina Chaminade and \\ Monica Plechero
}

\subsection{Introduction}

This chapter discusses the role of combinatorial knowledge and its multiscalarity in shaping the transformation paths of local productive systems (LPSs) that are affected by the gales of contemporary technological change. Specifically, we look at how access to - and the combination of - different knowledge bases at different territorial scales (local/regional, national, international/global) can support different paths of industrial upgrading for LPSs in the face of the challenges posed by Industry 4.0 (I4.0). We adopt the I4.0+ (plus) perspective defined in Chapter 1, which aims to address sustainable development.

Local and regional transformation paths increasingly rely on complex knowledge dynamics (Grillitsch et al., 2018), which require different types of knowledge to inter-relate in order to support some degree of innovativeness in local systems (Asheim et al., 2017; Grillitsch et al., 2017). Such knowledge dynamics refer not only to knowledge that has different degrees of transferability across spaces (tacit vs. codified knowledge), but more crucially involve different knowledge bases: analytic (science-based), synthetic (engineeringbased) and symbolic (cultural-based) (Asheim and Coenen, 2005; Asheim and Gertler, 2005).

Traditionally the literature on knowledge bases has argued that synthetic and symbolic knowledge - both with a high tacit content - tends to be accessed only when actors are in close proximity and with limited international interactions (Martin and Moodysson, 2011, 2013). In contrast, analytic knowledge - which has a higher codified content - tends to be accessible at a wider geographical scale. However, recent evidence suggests that synthetic and symbolic knowledge can also be sourced at an international level, which extends the possibility for accessing and combining all knowledge bases at different geographical scales (Martin et al., 2018).

In this chapter, we build on this suggestion and propose a novel conceptual framework that attempts to match different transformative paths with different forms of combinatorial knowledge creation. We assume that matching might involve different knowledge bases that are sourced at all geographical scales, 
from regional to global. Furthermore, we will discuss how effective sourcing depends on the use of specific mechanisms and on the presence of place-specific conditions (Section 4.2).

This extended framework will be applied to better understand how access to knowledge and any of its combinations can shape alternative models of value creation in LPSs that are embarking on transformative or renewed paths of development in order to take advantage of the opportunities opened up by I4.0. In particular, digital technologies characterize the core of the I4.0 model, and may unlock and enable new value-creation solutions within LPSs that will impact not only on the economic growth of places, but also on their societal development (OCSE, 2016; World Bank, 2017). On the one hand, I4.0 is pushed by the increasing importance of analytical/scientific knowledge supported by digital coding. On the other hand, the outcomes of innovation processes underpinned by I4.0 include an ever-deeper combination of product, service and societal contents. This implies the necessity of accessing both synthetic/engineering and symbolic/cultural knowledge on complex multi-scalar settings (Section 4.3).

In the final section in the chapter, we will discuss these issues in relation to a number of cases studied within the MAKERS project.

\subsection{Access and combination of different knowledge bases in the transformative paths of LPSs}

\subsubsection{Knowledge bases and local path transformation}

As already noted, there is a stream in the innovation literature that argues that local/regional path transformation is favoured when different types of knowledge can be accessed, combined and effectively integrated. ${ }^{1}$ Combining different types of knowledge is indeed a distinct feature of current innovation processes transforming the nature of a large number of industries (Strambach and Klement, 2012; Grillitsch and Trippl, 2014, Corradini and De Propris, 2015). This is even more so in the context of both disruptive technological challenges brought by Industry 4.0 and when there is a need to pursue sustainable societal as well as environmental goals (Strambach, 2017). ${ }^{2}$

Attending to the degree of codification and the processes of knowledge creation, Asheim and Coenen (2005) and Asheim and Gertler (2005) distinguish between three types of knowledge bases:

- Analytic knowledge (science-based) is often created with the application of experiment-based methods. The value is extracted from the application of scientific principles and theoretical modes of learning. Much of its content can be transferred in a codified form (lectures, reports, publications and patents). Often firms rely on collaboration with research organizations for its creation and on research and development (R\&D) laboratories for its absorption. 
- Synthetic knowledge (engineering-based) relies on inductive processes of problem solving. In production contexts, it is associated with the engineering of new results emerging from doing, using and interacting (DUI) forms of learning (Jensen et al., 2007). The value can be extracted by means of socialization and synthesis of the existing knowledge (Herstad et al., 2014).

- Symbolic knowledge (cultural-based) concerns cultural contents and aesthetic as well as immaterial values. Its creation relies on a variety of heritage and life notions and images elaborated by means of trained artistic and cultural intuition. The value can be extracted from creativity and contextualized sense making. Whilst it is highly place-specific, as the interpretation of images, design and symbols varies significantly from one location to another, it can also be embedded in artefacts and media communications by means of design and various types of applied and performing arts.

Due to its mostly codified nature, analytical knowledge could be accessed across large geographical distances and, consequently, industries dominated by analytical knowledge bases tend to display a high propensity towards establishing international networks. Synthetic knowledge, meanwhile, combines elements that are tacit and codified in nature, and, as a consequence, such knowledge can be acquired more through local networks and only to a lesser extent through international networks. Finally, symbolic knowledge-creation processes tend to rely significantly on local knowledge networks (Bathelt et al., 2004; Martin, 2011).

When we consider processes of local or regional transformation, should LPSs' access to and ability to combine different knowledge bases be limited, a high risk of path exhaustion if not decline would materialize. On the contrary, when different types of knowledge can be accessed and effectively combined by local actors, this may lead to some forms of path upgrading. Meanwhile, new path creation would require a high degree of combinatorial knowledge, which often implies an extensive use of differentiated knowledge bases as well as complex multi-scalar interactions. ${ }^{3}$

While some of the initial literature on knowledge bases tends to suggest that synthetic and symbolic knowledge will be sourced in local and regional networks while analytical knowledge can be sourced at the international level (Martin and Moodysson 2011, 2013), Martin et al. (2018) suggest that different knowledge bases supporting the processes of transformation of LPSs can be acquired at different scales depending on the needs and capabilities of specific firms. However, they fall short of explaining how this occurs and which mechanisms are more likely to be activated to access the different types of knowledge and at which different geographical scale. This chapter fills this conceptual vacuum.

\subsubsection{Multi-scalar mechanisms for knowledge access and combination in local productive systems and knowledge-led transformative paths}

A key issue that emerges from the literature that links knowledge bases to transformative paths is that effective combinatorial knowledge processes require 
local and global spaces to be bridged or connected. Such connections need to be better understood. At the local level, firms and supporting organizations may use a variety of mechanisms to access different knowledge bases (Trippl et al., 2009), such as market mechanisms, networks (e.g. alliances), hierarchies (e.g. via the operations of multi-national corporations) and spill-overs (e.g. mobility). In particular, knowledge is typically exchanged in markets when it is embodied in goods or services whose value is potentially easy to measure. Such embodied knowledge is likely to correspond to analytic or codified synthetic types of knowledge. Typical examples would be the use of patents for a new drug development or the acquisition of machinery for a specific engineering process.

Fragments of all types of knowledge may be accessed via unintended spillovers associated with human capital mobility, the monitoring of competitors, or informal single or repeated face-to-face contacts. Spill-overs tend to occur in close geographical proximity, although larger geographical distances are not excluded, for example, through international mobility (Rosenkopf and Almeida, 2003; Song et al., 2003) or temporary geographical proximity (Torre, 2008).

Networks, on the other hand, are based on trust and reciprocity (Powell, 1990). The reciprocal character of network relationships implies that actors have similar or complementary absorptive capacity as well as frequent face-to-face interactions and/or the sharing of habits and collective rules. Networks are a good mechanism for the transmission of know-how and know-who, and, in that respect, they are likely to be used for the collaborative transfer and the absorption of tacit contents prevailing in synthetic and symbolic knowledge. Networks for knowledge creation and innovation can take different forms: R\&D contracts, alliances, research consortia, epistemic communities or communities of practice.

Finally, hierarchies, which can be inter-firm and intra-firm, are mainly based on power enforcement together with the sharing of private rules, common routines or a history of previous interactions. Those characteristics also reduce institutional distance across space (Martin and Salomon, 2003). By opening subsidiaries in different locations, multi-national corporations (MNCs) can access and absorb tacit and codified synthetic knowledge belonging to different scientific and technological fields that has been accumulated in different countries or regions around the world (Kafouros et al., 2012).

The propensity of firms to use different mechanisms to access distant knowledge will ultimately depend on the availability and transferability of knowledge as well as the capabilities of firms. By availability, we refer to the degree of concentration of that knowledge in specific regions around the world. The sources of highly novel analytic knowledge, highly specialized synthetic knowledge or key symbolic knowledge are sparse and often highly concentrated in specific locations (knowledge hubs). This means that firms located in knowledge hubs have an advantage in terms of access to such knowledge without the need to engage in extra-regional links. However, having access to knowledge is not enough. The ability of the organization to tap into pools of knowledge is strongly related to its absorptive capacity. Transferability is the possibility to 
transmit and receive knowledge without noise, bias or leaks, and depends on the degree of codification. Hence, availability, absorptive capacity and transferability determine what mechanism firms avail themselves of to access knowledge at different geographical scales.

The question is therefore as follows: at what different geographical scales do the above-mentioned mechanisms help firms and related organizations access different knowledge bases and trigger combinatorial knowledge creation processes enabling local transformations?

We focus our analysis on LPSs (Becattini and Rullani, 1996): these are (relatively) small regions (urban or rural areas, industrial districts, etc.) featuring one or a few productive specializations, which are more or less complementary. The specializations are related to the activity of a cluster of firms and supporting business and public organizations operating in the place. Productive decisions and activities have key roots in local business and socio-cultural and institutional networks.

Table 4.1 provides a schematic summary of the main mechanisms supporting the access of LPSs to different types of knowledge bases that can be leveraged at different geographical scales. The appropriateness of the mechanisms and their role for path transformation in LPSs depend on the wealth of knowledge sources in LPSs and the type of proximity that can be used when accessing different knowledge bases. ${ }^{4}$

In transformative processes, market mechanisms are used by companies to access internationally available analytic knowledge, for example, through patents (Herstad et al., 2014). However, firms whose innovative processes are driven by the creation and/or the development of new analytic knowledge either cluster in highly innovative hubs around the world or tend to link to key players themselves located in international knowledge hubs. Networking in this case is a preferable mechanism for distant interactions. Firms located in LPSs with strong research infrastructure are also more likely to have high technological capabilities enabling them to actively participate in research networks on a global scale.

Networks and spill-overs facilitating or implying face-to-face interaction are likely to be used intensively for accessing synthetic knowledge at different geographical scales. Networks in general are likely to work better at local or national levels where institutional distance is limited (Martin and Moodysson, 2013; Mattes, 2012). When accessibility to synthetic knowledge is low or networks and spill-overs at the local level fail to provide new inputs for generating value, firms may decide to use the hierarchical channel by opening, for example, a subsidiary abroad (offshoring of R\&D) to acquire synthetic knowledge from a distant location (Liu et al., 2013). The MNC might bring in knowledge accumulated from networks with other places that can be reapplied and reused differently in the host location.

On the other hand, symbolic knowledge is highly context-specific and tacit, moving with individuals or being embedded in specific communities (e.g. communities of practice or epistemic communities). Access to symbolic 
Table 4.1 Some key mechanisms for firms in LPSs to access different knowledge bases in a multi-scalar setting

\begin{tabular}{|c|c|c|c|c|c|c|c|c|}
\hline 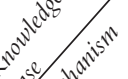 & $\begin{array}{l}\text { Markets } \\
\text { (within LPS) }\end{array}$ & $\begin{array}{l}\text { Markets } \\
\text { (beyond LPS) }\end{array}$ & $\begin{array}{l}\text { Spill-overs } \\
\text { (within LPS) }\end{array}$ & $\begin{array}{l}\text { Spill-overs } \\
\text { (Beyond LPS) }\end{array}$ & $\begin{array}{l}\text { Networks } \\
\text { (within LPS) }\end{array}$ & $\begin{array}{l}\text { Networks } \\
\text { (beyond LPS) }\end{array}$ & $\begin{array}{l}\text { Hierarchies } \\
\text { (within LPS) }\end{array}$ & $\begin{array}{l}\text { Hierarchies } \\
\text { (beyond LPS) }\end{array}$ \\
\hline Analytical & $\begin{array}{l}\text { Trade } \\
\text { (e.g. patents) }\end{array}$ & $\begin{array}{l}\text { Trade } \\
\text { (e.g. patents) }\end{array}$ & & & $\begin{array}{l}\text { R\&D } \\
\text { collaboration } \\
\text { (e.g. research } \\
\text { consortium) }\end{array}$ & $\begin{array}{l}\text { Domestic/international } \\
\text { R\&D collaboration, } \\
\text { but some cognitive/ } \\
\text { organizational } \\
\text { proximity necessary) } \\
\text { (this can be key } \\
\text { for knowledge } \\
\text { creation) }\end{array}$ & & \\
\hline Synthetic & $\begin{array}{l}\text { Trade (market } \\
\text { technologies/ } \\
\text { goods for } \\
\text { codified aspects } \\
\text { of engineering } \\
\text { process) }\end{array}$ & $\begin{array}{l}\text { Trade (market } \\
\text { technologies/ } \\
\text { goods for } \\
\text { codified } \\
\text { aspects of } \\
\text { engineering } \\
\text { process) }\end{array}$ & $\begin{array}{l}\text { Local mobility } \\
\text { of human } \\
\text { resources } \\
\text { and face- } \\
\text { to-face } \\
\text { interactions }\end{array}$ & $\begin{array}{l}\text { International } \\
\text { mobility, } \\
\text { temporary } \\
\text { geographical } \\
\text { proximity }\end{array}$ & $\begin{array}{l}\text { Networks } \\
\quad \text { (often } \\
\text { informal) }\end{array}$ & $\begin{array}{l}\text { Domestic networks } \\
\text { (also informal, } \\
\text { but institutional } \\
\text { proximity is } \\
\text { necessary) }\end{array}$ & $\begin{array}{l}\text { R\&D } \\
\text { offshoring } \\
\text { from MNCs } \\
\text { in loco } \\
\text { (this can be } \\
\text { key for } \\
\text { knowledge } \\
\text { renewal) }\end{array}$ & $\begin{array}{l}\text { International R\&D } \\
\text { offshoring (e.g. in } \\
\text { specialized hubs) } \\
\text { (this can be key } \\
\text { for knowledge } \\
\text { renewal) }\end{array}$ \\
\hline Symbolic & & & $\begin{array}{l}\text { Local mobility } \\
\text { of human } \\
\text { resources }\end{array}$ & $\begin{array}{l}\text { National/ } \\
\text { international } \\
\text { recruitment } \\
\text { of skilled } \\
\text { labour }\end{array}$ & $\begin{array}{l}\text { Networking } \\
\text { within local } \\
\text { community } \\
\text { (e.g. } \\
\text { community } \\
\text { of practice) }\end{array}$ & $\begin{array}{l}\text { International } \\
\text { communities } \\
\text { (e.g. in epistemic } \\
\text { communities, some } \\
\text { social proximity is } \\
\text { necessary) } \\
\text { (this can be key } \\
\text { for new sense } \\
\text { making) }\end{array}$ & & \\
\hline
\end{tabular}

Source: Authors' elaboration. 
knowledge is therefore expected to be based on networks and spill-overs. Social proximity, temporary proximity or international mobility can compensate for a lack of geographical proximity (Gertler, 2008; Martin and Moodysson, 2011). This is particularly crucial when there is a need for companies in an LPS either to link to places where new creative processes are taking place or to inject a new sense of interpretation and new intangible values in established cultural contexts.

The framework suggested here helps us to draw connections across the fragmented empirical evidence on the geography of different knowledge bases. In particular, by linking knowledge characteristics, types of proximity and mechanisms of transmission, it is possible to reach a better understanding of how different knowledge types at different geographical scales can generate value for LPSs embarking on sustainable and transformative paths.

\subsection{Geographical scales of competing models in Industry 4.0 technological transformation}

Drawing on the conceptual framework presented in Chapter 1 in this volume, it is possible and desirable to include considerations of social and environmental sustainability within and around the pure technical core of the current digital and science-driven industrial transformation that goes by the name of Industry 4.0. Such inclusion leads to an expanded perspective, so-called Industry 4.0 plus $(\mathrm{I} 4.0+)$, that implies the generation of alternatives to mainstream models of value creation and distribution, which otherwise would seem to respond deterministically to 'natural' efficiency-driven arguments. Such Industry 4.0 efficiency-driven arguments would include the centrality of smart and webbed factories and platforms, the ruling of large and multi-national firms, combining mass-customization of products and a very high intensity of capital in core processes, together with market domination, skill polarization, and the digitally driven deterioration of the citizen's control over choices on local public and common goods.

In contrast, I4.0+ is based on the idea that the new technologies should and could be addressed to help bringing sustainable growth, a wide mobilization of human capabilities, and prosperity within territories and their populations of firms, workers and families, as well as between territories. Specifically, the I $4.0+$ perspective aims at better understanding alternatives in local and regional industrial development that face the current challenges of social, economic and environmental sustainability in models of value creation and distribution.

\subsubsection{Alternative I4.0+ models of value creation and distribution}

The alternatives to conventional 'efficiency'-based models concern various aspects. We refer to Bellandi et al. (2018) for a broader discussion, but here we evoke briefly the core contents of the composite solutions supporting I4.0+ models as alternatives to the technocratic and centralistic mainstream: 
- Inter-dependencies around smart networked micro-manufacturing (SNMM): small factories are able to incorporate new digital-based technologies in production processes led by craft skills and care. Small firms managing such factories access international networks of designers, customers and suppliers. Localized pools of SNMM drive a transformation of LPSs specialized in manufacturing into product-service systems incorporating territorial servitization (Bellandi and Santini, 2019).

- Digital participation and distributed service provision: an open and enlarging set of digital-based services would allow a territorial servitization of LPSs, with the latter being strong and non-dependent on large oligopolistic providers. Services here include trade, finance, advertising, labour selection and training, enterprise resource planning and relationship management, collaborative knowledge and innovation networks (De Maggio et al., 2009). They may develop on local platforms where small firms and citizens are granted digital sovereignty, information freedom and open access (Morozov and Bria, 2018). Local counterbalancing power should be inserted within and supported by national and supranational anti-trust actions.

- Makers and smart skills: operative well-trained skills are still crucial in key phases of value chains if production digital-based technologies are developed not in substitution, but in support of professional/creative processes (Barzotto and De Propris, 2019). This would allow LPSs to meet customer-specific demand in complex ways and expand SNMM. Examples are the matching of materials of variable quality with multi-purpose tools (I4.0 as well), related quality control, prototypes of new digital-based production processes, etc. (Bettiol and Micelli, 2014).

- Quadruple-helix governance of projects of sustainable socio-economic development: integrated productive development and innovation projects involve and connect constellations of actors. They include engaged developmental universities, local/regional networks of SMEs non-captured by oligarchies, anchored MNCs forced to relinquish predatory strategies, and civic society, with its more or less local social networks and supporting social innovation towards a common good for a sustainable life (Aoyama and Parthasarathy, 2016).

The contents of alternative manufacturing models under I4.0+ suggest innovation processes that could promote transformative paths for LPSs characterized by a networked plurality of firms and organizations and by manufacturing specializations grown out of the previous wave of technological change (Perez, 2009). It is apparent that a wide and coordinated introduction of such contents would imply the access, absorption and creative combination of different types of knowledge. This would be the basis for paths of accentuated upgrading in these systems.

\subsubsection{Knowledge bases and multi-scalar mechanisms in I4.0+}

We now apply the framework presented in Section 4.2 to the models discussed just above under the $14.0+$ perspective in order to derive general suggestions 
on the relations between transfer mechanisms and the multi-scalar setting for knowledge access and combination that drive transformations in LPSs. The core of such a model, we would suggest, lies in SNMM solutions. ${ }^{5}$ Within and around such core, there is a need for the development of digital participation and distributed service provision; the diffusion of neo-maker competences, combining artisan attitudes and digital skills; and the quadruple-helix governance of projects of sustainable socio-economic development.

Our concern now is to understand what the geographical scale of processes of knowledge access and combination for innovation might be both for the mainstream technocratic and centralistic models leading to cyber-physical production organizations and for the alternative distributed model (inspired to I4.0+). In particular, we want to investigate under what conditions LPSs characterized by a networked cluster of independent specialized business organizations can pursue processes of innovation incorporating the alternative model, and using this support paths of sustained upgrading and regional transformation (path renewal or even path creation).

Starting from the productive core, the basic feature that the alternative distributed model shares with the centralistic efficiency-driven model is the importance of codified knowledge in terms of digital coding and software development underlining the I4.0 technologies or their applications. R\&D on new types of coding and new applications to multiple fields of scientific and technological problems obviously relates to efforts to create analytical knowledge. Such efforts are concentrated, though non-exclusively, in few 'hot' high-tech hubs around the word. The results of their efforts may be in principle transmitted in codified form at a distance. However, the successful transfer and acquisition of such results require absorptive capacity; in other words, they necessitate pre-existing digital competences internal to users-firms, either to generate new combinations between incoming knowledge and the knowledge bases already present in the firm or just to adopt new technologies developed elsewhere.

Given the breadth and the speed of the development of new digital technologies, the support of specialized intermediary agents in LPSs is also needed.They are knowledge-intensive business or service (KIBS/KIS) providers that combine parts of the analytical knowledge with the synthetic knowledge related to the features and idiosyncrasies of specific technological, production or organizational fields of firms in the LPS. In certain cases, KIBS/KIS providers also combine significant components of symbolic knowledge, as with design-driven innovation (Cooke and Eriksson, 2011). Such combinatorial services may be more or less standardized or customized to the needs of particular users.

Large firms can easily access I4.0 technologies. With their large demand, they rely on the services of national and international KIBS/KIS providers by means of relational contracts and formal networks. Temporary geographical proximity with such international KIBS/KIS providers by means of resident teams is to be expected during the developmental phases or to resolve unexpected shocks in usage, whereas ordinary maintenance and upgrading can be supported at a distance. 
Trying to navigate the technological requirements of I4.0 technologies raises very different questions for non-centralized LPSs aiming at alternative distributed production models. Here we see two main challenges. Firstly, the single business organizations (even local entities of MNCs) included in these LPSs ordinarily cannot represent a large demand of service within the portfolio of national or international providers of KIBS/KIS. Secondly, it seems plausible that LPSs addressing alternative models to I4.0 should find their competitive advantage in market fields featured by a continuous stream of differentiation, incremental innovations and decentralized creativity, combining the personalization of products and artisan ingenuity. Here, synthetic and symbolic knowledge have key functions in terms of value creation, together with an increasing degree of codification and automation in various phases of the value chain. A real servitization of the variable and differentiated digital components needed by firms belonging to the core productive specializations of the LPS would need geographical proximity and versatility, and the help of various types of mechanisms, also including spill-overs and informal networks. This is a territorial servitization (Lafuente et al., 2017), whereby local KIBS/KIS work in stable contact with the LPS users (Bellandi and Santini, 2019). On the other hand, if the LPS is not able to express an effective territorial servitization, digital services may be acquired by LPS users in standardized forms by means of market relations. This would be a situation where the alternative distributed model to I4.0 has reduced the chances of success. Large national and international providers of KIBS/KIS may also be involved in LPSs. If there is the possibility to develop digital platforms servicing a critical mass of local users with some specific smart and connectivity-enabling components, then large providers may find it profitable to invest in local entities ( $R \& D$ outsourcing).

Around the productive core, the 'alternative way' also needs to expand from business organizations and networks to wider society. Neo-makers, local digital sovereignty and quadruple helix methods of governance express a function played by the contexts of out-of-the factory life that is deeper and larger than just consumption and labour supply. It concerns knowledge access, value creation and value distribution. Giacomo Becattini saw this relation between infactory and out-of-the-factory life at work in the development of industrial districts. He pointed to the neo-artisan tendencies opening windows of opportunities in many non-centralized LPSs in advanced economies in the second half of the 20th century. 'The ever-changing multiplicity of needs demands an exit of capitalist production from the "factory", and its return to a plenty of "laboratories" within the society, searching for artisanship, customized service, ties with historical-cultural and environmental sources of peculiar experiences' (Becattini and Bellandi, 2006: 86). And in the words of Sebastiano Brusco: 'Both the "in-factory" and "out-factory" spheres contribute directly to shape not only the quality of civil life but also productivity levels and market competitiveness' (Brusco, 1996: 155-156).

This perspective on the societal side extolled the importance of geographical and social proximity. The local contents of synthetic and symbolic knowledge, 
which are at the core of DUI modes of learning and innovation (Jensen et al., 2007), were also drawing from the experiences of ordinary life. It was acknowledged, nonetheless, that trans-local networks, local agents of versatile integration and local centres of services were also needed in order to link the LPS with the development of scientific and technological frontiers (Becattini and Rullani, 1996).

The effective involvement of the societal side is also key in the definition of distributed non-centralistic approaches to the contemporary digital transformation under the $\mathrm{I} 4.0+$ perspective. The opportunity to combine, at various degrees of breadth and depth, the different knowledge bases is open to more than a few bridging, integrating, gatekeeping business actors. In principle, it may involve a multitude of business, socio-cultural and institutional agents.

What differentiates the capacity of LPSs to innovate and take upgrading paths of transformation is both the effective diffusion of combinatorial competencies and the collective capability to share a vision on path transformation. The vision may be led by the idea of a key role played by the development of new analytic or synthetic knowledge. However, the vision in itself has necessarily high local and non-local symbolic contents, since it requires a creative exploration of the opportunities offered by I4.0, in which new values and new senses for interpreting society are collectively constructed (Rullani and Rullani, 2018).

Furthermore, such a vision should be supported by collective (public and private) investments in specific open and multi-disciplinary platforms for the development of combinatorial capabilities and digitally based innovations. The development of such platforms necessarily rests on analytic/scientific knowledge. Weak combinatorial capabilities would probably force the LPS down towards lower paths of transformation, which might plug the LPS within centralistic routes of I4.0 or more generally force it to become subservient to global logics by feeding its economic resources to global chains of production and consumption (Storper, 2009: 155-156).

\subsection{Examples from the MAKERS project}

In this section, we present some applications of the framework developed in the previous sections to the interpretation of the geographical scales of knowledge links relevant to path transformation in LPSs under I4.0+ perspectives. Facts and reflections are collected from eight cases discussed within the reports of the MAKERS project (see Chapter 1 of this volume). ${ }^{6}$

We would partition the eight cases into three sub-sets. The first one includes the transformations of the 'paper province' in the Swedish Värmland Region and the Viareggio yachting industry in the Tuscany region (Italy). The second sub-set consists of three textile-based LPSs in Prato (Tuscany), Borås (in western Sweden) and St Gallen, Appenzell and Glarus (in eastern Switzerland). The third sub-set corresponds to the mechatronic LPS in Veneto (Italy), the automation LPS in Värtmanland (Sweden) and the life sciences LPS in Tuscany. 
Only the Tuscany life sciences LPS has a strong basis in a metropolitan area (Florence), whereas the eastern Switzerland LPS is confined within a set of relatively small cities and it includes traditionally a related variety of sectors around the decreasing textile specialization. All the other LPSs are in reality industrial districts supported by different types of regional innovation systems.

In what follows, we focus in particular on the cases of the first sub-set highlighted, that is, the traditional medium-tech industries (the pulp and paper industry in Värmland and the yachting industry in Viareggio), and their geographical scales, knowledge bases and path transformation under $\mathrm{I}_{4} . \mathrm{O}+$ perspectives. Cases falling under the other two sub-sets will be discussed more briefly so as to provide some complementary observations at the end of the section.

The pulp and paper industry in Värmland and the yachting industry in Viareggio have developed in the past few decades as the main manufacturing specialization of the respective LPSs, with competitive advantages grounded in the relation between a strong basis of synthetic knowledge and specific locational factors. Both cases are interesting because such locational factors have been turned in the last few decades into a strong source of symbolic knowledge, still combining with local synthetic knowledge, but also attracting the activity of providers of analytic knowledge. Both cases can be taken as examples of alternative I4.0+ models that challenge the narrower definition of I4.0 and allow us to look at the geographical scale and knowledge bases of paths to upgraded transformation.

\subsubsection{Combinatorial knowledge bases and multi-scalar mechanisms in the transformation of pulp and paper in Värmland (Sweden)}

In this case, the locational factor is represented by the proximity to a large land of forests, an abundance of woods that may be easily treated for pulp extraction, and a tradition of preservation of the natural patrimony. The pulp and paper industry has developed for almost a century, with a strong presence of manufacturing plants and R\&D laboratories as part of some large national and international companies, together with a population of specialized SMEs, also including those related to forest works.

Chapter 6 in this volume by Ramirez illustrates the emergence of a transformation path, from the traditional pulp and paper specialization to a more differentiated and analytic knowledge-intensive path, which is called the 'forestbased bio-economy', within a plan promoted by a local cluster organization in the last decade. The enduring basis is a multiplicity of nuclei of manufacturing synthetic knowledge, in dialogue with the synthetic knowledge of forestrelated activities. Crucial manufacturing synthetic knowledge is hosted within the larger plants and accessed thanks to networks and spill-overs at the local level or through technologies partly acquired on external markets. The access to analytical knowledge has also been important both for the absorption and the development of some more capital-intensive technologies in pulp processes, 
and for an environmentally sustainable approach to the large-scale exploitation of wood resources.

The cluster initiative in recent years has tried to promote the shift to an economy specialized in the production of renewable biological resources, also with the support of digital technologies. In this cluster initiative, a critical role seems to be played by the strategic orientation of national and regional innovation systems, investments by MNCs embedded in the local economy and the role played by technological intermediaries. New analytic knowledge is developed thanks to the presence of R\&D laboratories of large MNCs firms, and networks with local and national universities are also supportive in this respect.

The cluster management agency, the national innovation agency and the international technological intermediaries have been able to elaborate an integrated vision and strategy that has also pulled a wave of investments from distant headquarters of MNCs. This includes reference to the highly symbolic contents of the 'bio-economy' (a combination of the local forest tradition, the green strategy of the national innovation system and EU programmes). Moreover, it provides an answer to relevant manufacturing problems (e.g. the disposal of industrial waste), with the interaction between traditional synthetic know-how (accessed by local spill-overs, informal networks and hierarchies) and analytic knowledge (accessed by local formal network and the $\mathrm{R} \& \mathrm{D}$ laboratories of large vertically integrated firms that can digitally control all the phases of the production processes). Around the productive core, the cluster initiative includes projects aimed at diffusing digital competences and increasing the capacity of small local ICT services to access the new demand of the forest-based bio-economy (see Ramirez, Chapter 6 in this volume).

All in all, this case shows a virtuous combination of all three knowledge bases, accessed with appropriately different mechanisms at different spatial scales. The LPS seems ready for accomplishing a path transformation that could be seen, if realized, as a case of successful path creation (see Table 4.2).

\subsubsection{Combinatorial knowledge bases and multi-scalar mechanisms in the transformation of the luxury yachting industry of Viareggio}

In this second case, the locational factor is represented by the fact that the luxury yachting industry of Viareggio is located adjacent to an important Tuscan seaside tourist attraction, around Viareggio and Forte dei Marmi, which is associated with an image of high-quality recreational products and services.

As detailed in Chapter 5 in this volume by Bellandi, De Propris, Santini and Vecciolini, the long-term synthetic knowledge base of the yachting system is artisan know-how in small shipbuilding. The industry has evolved in the last few decades thanks to the international inflow of analytic knowledge that has allowed the introduction of new advanced materials, constructive solutions and 
Table 4.2 MAKERS cases: combination of knowledge bases in a multi-scalar setting in the pulp and paper industry in Värmland

Path creation towards I4.0+: use of combined analytical, synthetic and symbolic knowledge at different geographical levels transforming a paper and pulp specialized LPS into a forest based bio-economy LPS

\begin{tabular}{|c|c|c|c|c|c|c|c|c|}
\hline & $\begin{array}{l}\text { Markets } \\
\text { (within } \\
\text { LPS) }\end{array}$ & $\begin{array}{l}\text { Markets } \\
\text { (beyond LPS) }\end{array}$ & $\begin{array}{l}\text { Spill-overs } \\
\text { (within LPS) }\end{array}$ & $\begin{array}{l}\text { Spill-overs } \\
\text { (beyond } \\
\text { LPS) }\end{array}$ & $\begin{array}{l}\text { Networks } \\
\text { (within LPS) }\end{array}$ & $\begin{array}{l}\text { Networks } \\
\text { (beyond LPS) }\end{array}$ & $\begin{array}{l}\text { Hierarchies } \\
\text { (within LPS) }\end{array}$ & $\begin{array}{l}\text { Hierarchies } \\
\text { (beyond LPS) }\end{array}$ \\
\hline Synthetic & & $\begin{array}{l}\text { Market } \\
\text { technologies } \\
\text { related to } \\
\text { synthetic } \\
\text { processes }\end{array}$ & $\begin{array}{l}\text { Spill-over from } \\
\text { domestic/ } \\
\text { international } \\
\text { MNCs within } \\
\text { pulp industry } \\
\text { located in LPS }\end{array}$ & & $\begin{array}{l}\text { Interactions at local level } \\
\text { between traditional } \\
\text { and forest-related } \\
\text { activities (mediated by } \\
\text { cluster organization) }\end{array}$ & $\begin{array}{l}\text { Bridging role in } \\
\text { international } \\
\text { networks played } \\
\text { by local MNCs } \\
\text { and technological } \\
\text { intermediaries }\end{array}$ & $\begin{array}{l}\mathrm{R} \& \mathrm{D} \\
\text { offshoring } \\
\text { from } \\
\text { MNC } \\
\text { located in } \\
\text { LPS }\end{array}$ & \\
\hline Symbolic & & & & & $\begin{array}{l}\text { Bio-economy } \\
\text { concept: shared } \\
\text { values at local level } \\
\text { (emerging from a } \\
\text { cluster initiative) }\end{array}$ & $\begin{array}{l}\text { Bio-economy } \\
\text { concept: shared } \\
\text { values with } \\
\text { national and } \\
\text { international } \\
\text { stakeholders }\end{array}$ & & \\
\hline
\end{tabular}

Source: Authors' elaboration on MAKERS cases, www.makers-rise.org. 
gadgets in the building of top-end boats for recreational uses. Nowadays, the LPS is specialized in the production of luxury yachts, with highly sophisticated and price-inelastic demand from wealthy people.

Each luxury yacht is almost a unique piece, with unique design, artisanship and sophisticated technology, including solutions absorbing many types of smart and connectivity digital components. Analytical knowledge is accessed in various ways, but a key role is played by the R\&D offices of the local shipyards (which correspond to the sectoral headquarters of large national and international companies), by formal networks with research organizations supported by a regional intermediary organization, and by market relations and informal networks with providers of technology at local, national and international levels. However, R\&D is mainly aimed at the creation of new symbolic knowledge for improving design rather than at the development of new analytic knowledge. Furthermore, the construction of each yacht is highly demanding in terms of practical learning and creativity that involves a large number of specialized SMEs and artisans. This local core of synthetic knowledge is based on reciprocal spill-overs, formal networks with the shipyards and informal networks with the providers of technology. Small-scale and personalized information and communications technology (ICT) services for the yacht industry are granted by an ICT cluster based in the nearby city of Pisa. Various types of initiatives (local fairs, professional schools, etc.) can involve the local citizens in shaping the destiny of the local industry, even if the growth of neo-maker competences seems quite weak and given that related quadruple-helix projects are not surfacing at the moment. Indeed, the main knowledge input into the LPS comes from the out-factory relationships associated with requests and demands raised by wealthy buyers from around the world, as well as by the skippers employed by the ship owners.

While the case of this LPS appears quite unique, the luxury yacht industry may be seen as an exemplification of the extreme personalization and coproduction that might characterize top-end and niche industries within the I $4.0+$ model. The uniqueness of each product, the continuous introduction of new solutions and the adoption of the latest technologies make it difficult to classify what path the LPS is following or can follow. Perhaps it points to a class of paths of 'continuous' renewal, where the creativity that drives personalization may become, in subsequent steps, a source of inspiration for part of the local community to reuse the acquired technologies and develop other related business or civic services. This case is led by the development of symbolic and synthetic knowledge and the absorption of analytic knowledge (see Table 4.3). In particular, symbolic knowledge has strong local roots, but it demands multiscalar flows and mechanisms of creation and image building, combined with the absorption of new analytic and synthetic knowledge. Perhaps the local structure would not support local path creation, but the multi-scalar actors involved in the delivery of highly sophisticated unique products which are present at a local level could favour new value chains and path creation in other places (see Chapter 5 in this volume). 
Table 4.3 MAKERS cases: combination of knowledge bases in a multi-scalar setting in the luxury yachting industry

\begin{tabular}{|c|c|c|c|c|c|c|c|c|}
\hline & \multicolumn{8}{|c|}{ Continuous path renewal driven by extreme personalization: development of new symbolic and synthetic knowledge with absorption of analytic knowledge } \\
\hline Analytical & & $\begin{array}{l}\text { Digital } \\
\text { technologies } \\
\text { advance material, } \\
\text { new constructive } \\
\text { solutions }\end{array}$ & & & $\begin{array}{l}\text { Networks with research } \\
\text { organizations; networks } \\
\text { with providers of } \\
\text { technologies (weak } \\
\text { R\&D) }\end{array}$ & $\begin{array}{l}\text { National and } \\
\text { international networks } \\
\text { with providers of } \\
\text { technologies (weak } \\
\text { R\&D) }\end{array}$ & & \\
\hline Synthetic & & & $\begin{array}{l}\text { Local } \\
\text { companies } \\
\text { reciprocal } \\
\text { spill-over }\end{array}$ & & $\begin{array}{l}\text { Formal networks within } \\
\text { the shipyards; } \\
\text { informal networks } \\
\text { with providers of } \\
\text { technologies }\end{array}$ & & & \\
\hline Symbolic & & & & & $\begin{array}{l}\text { R\&D collaborations for } \\
\text { new symbolic/design } \\
\text { knowledge }\end{array}$ & $\begin{array}{l}\text { R\&D collaborations for } \\
\text { new symbolic/design } \\
\text { knowledge }\end{array}$ & & \\
\hline
\end{tabular}

Source: Authors' elaboration on MAKERS cases, www.makers-rise.org. 


\subsubsection{Other cases from the MAKERS project}

Other cases from the MAKERS project help to provide supportive insights and qualifications. The textile cases ${ }^{7}$ illustrate transformation paths based on strong synthetic knowledge as they face the pressure of contemporary challenges. In all three cases, symbolic knowledge has acquired a key role, although playing partially different functions. In the Prato textile district, the image of creativity and quality of 'Made in Italy' is applied to the synthetic knowledge-based capability to rapidly produce an open and variable range of fabrics in very small batches (with a high degree of personalization and with some help given by digital technologies). Here, symbolic knowledge combines directly into strategies of high personalization of products, and the variety of mechanisms for accessing and absorbing new analytic knowledge is still quite low. In the Borås textile district, a strong governance and innovation system at the regional and national levels has promoted a vision that facilitated the absorption of new global analytic knowledge for the development and production of high-tech textile products. Symbolic knowledge seems to play a role in supporting strategic convergence around a collective strategy of analytic knowledge intensification, helped by multi-scalar mechanisms and integration. In the eastern Switzerland district of embroidery and textile machines, a local system supporting innovation and some civic initiatives, coupled with the presence of local diversified research and manufacturing capabilities, also networked at the national and international scales, help combine the synthetic knowledge basis with the creation of new symbolic and analytic knowledge. In this case, symbolic knowledge apparently plays both roles (i.e. personalization and vision).

Such cases appear to confirm some aspects detected in the first sub-set of cases above. Firstly, the high personalization of products demands the guidance of symbolic knowledge coupled with synthetic knowledge. Secondly, a greater opportunity for radical innovation and path creation seems to demand the guidance of analytic knowledge (accessed on a multi-scalar level) coupled with a subservient but necessary role of symbolic knowledge. In all cases, local access to synthetic knowledge cannot be dispensed in LPSs that seem to evoke alternative $\mathrm{I} 4 . \mathrm{O}+$ models. However, in the stronger cases, the reproduction and creation of synthetic knowledge is also an open field of local converge of multiscalar strategies.

Finally, the third sub-set includes cases characterized by the greatest use of analytic knowledge. ${ }^{8}$ Even for these, while any path of upgraded transformation depends crucially on access to and the adoption of analytic knowledge, the extent and depth of the transformation cannot be related only to the degree of local capabilities related to analytic knowledge. In fact, paths consistent with the alternative I4.0+ model, like in Värtmanland, also critically require access to symbolic knowledge for the creative and absorptive functions and at different geographical scales, beyond the presence of strong local pools of synthetic knowledge. 


\subsection{Conclusions and further research}

The previous discussion linking knowledge bases, multi-scalarity and the transformation of LPSs brings some interesting insights for policies (particularly at the regional level) sustaining LPSs. Firstly, regional policies do not necessarily have to ensure that all three knowledge bases (synthetic, analytic and symbolic) are co-located in the same LPS. Contrary to what has often been argued in the literature, firms and other innovative organizations could access different knowledge even from distant locations. Regional policies aiming at strengthening LPSs therefore need to go hand in hand with more general policies supporting the use of mechanisms to access knowledge at other geographical scales. Which mechanisms are more adequate depends strongly on the type of knowledge base, the capabilities of the firms located in the region, and conditions allowing access to knowledge. It also depends on which type of model of path transformation is pursued. In particular, and in relation to the challenges of I4.0, it depends on the prevalent vision (e.g. centralistic and technocratic or noncentralistic and distributed) informing public policies and private strategies. Secondly, our framework could help extend policies in terms of considering why two firms in the same industry and with similar levels of innovativeness one located in a knowledge hub and the other one located in a peripheral region - may have very different configurations.

This chapter has some limitations. Firstly, applying a multi-scalar framework to knowledge bases, which brings in knowledge characteristics and meso- and micro- conditions, requires data that are beyond what is currently available. In the short term, dedicated firm-based surveys or case studies in different LPSs around the world could provide a starting point to conduct empirical analysis based on the proposed framework. Secondly, based on the premise that combinatorial knowledge-creating processes involves the sourcing of knowledge at different geographical scales, our focus has been on theorizing when and how these multi-scalar knowledge-sourcing processes will take place. Admittedly, while the sourcing of knowledge is paramount for innovation, it is only one part of combinatorial knowledge-base processes. Knowledge acquired externally needs to be further processed internally, inside both individual firms and related organizations - and among them - within LPSs. In other words, while this chapter provides some insights as to how different knowledge bases are sourced using different mechanisms at different scales, it does not discuss how the firm combines them into new knowledge. Other chapters of this book consider this more directly, in so doing looking in depth into some of the MAKERS project cases referred to above.

\section{Acknowledgements}

We gratefully acknowledge the support by the EU Horizon 2020 project MAKERS, which is a Research and Innovation Staff Exchange under the 
Marie Sklodowska-Curie Actions, grant agreement number 691192. All errors remain the authors' responsibility.

\section{Notes}

1 See in particular the special issue on knowledge bases in (2017) 93(5) Economic Geography.

2 In this latter case, the generation of value often derives from the convergence of unrelated knowledge bases taken from different sectorial contexts and recombined in traditional sectorial specialization (Grillitsch et al., 2017).

3 Various contributions develop concepts and cases around such relations. See Asheim et al. (2011, 2017); Chaminade et al. (2017, 2018); Grillitsch et al. (2017, 2018); Isaksen and Trippl (2016); Manniche et al. (2017); Trippl et al. (2017).

4 Another condition not discussed in this chapter is appropriability, which concerns how agents interpret and use the acquired knowledge for extracting value.

5 This also concerns analogous productive solutions outside manufacturing, with precision agriculture, sustainable tourism, creative industries, personalized welfare, etc. (Crespi et al., 2014).

6 A cautionary note is needed: underpinning research on the cases to which we refer was not developed directly for applying and testing of the interpretative framework illustrated here. Therefore, some implications concerning individual cases are speculative. Nonetheless, we are confident about the robustness of the overall comparative panel.

7 See Bellandi et al., Chapter 5 in this volume on Prato; the MAKERS report by Santini and Bellandi (2017), including the case of eastern Switzerland; and Chaminade et al. (2018) on Borås.

8 See Corò and Volpe (Chapter 7 in this volume) on the Veneto mechatronic LPS and the automation LPS in Värtmanland. For the life sciences LPS in Tuscany, See Chapter 6 in this volume.

\section{References}

Aoyama, Y. and Parthasarathy, B. 2016. The Rise of the Hybrid Domain. Collaborative Governance for Social Innovation. Cheltenham: Edward Elgar.

Asheim, B.T. and Coenen, L. 2005. Knowledge bases and regional innovation systems. Comparing Nordic clusters. Research Policy, 34(8), 1173-1190.

Asheim, B.T. and Gertler, M.S. 2005. The geography of innovation: regional innovation systems. In Fagerberg, J., Mowery, D. and Nelson, R. (eds), The Oxford Handbook of Innovation. Oxford: Oxford University Press.

Asheim, B.T., Boschma, R. and Cooke, P. 2011. Constructing regional advantage: Platform policies based on related variety and differentiated knowledge bases. Regional Studies, 45(7), 893-904.

Asheim, B., Grillitsch, M. and Trippl, M. 2017. Introduction: combinatorial knowledge bases, regional innovation, and development dynamics. Economic Geography, 93(5), 429-435.

Barzotto, M. and De Propris, L. 2019. Skill up: smart work, occupational mix and regional productivity. Journal of Economic Geography, 19(5), 1049-1075. 
Bathelt, H., Malmberg, A. and Maskell, P. 2004. Clusters and knowledge: local buzz, global pipelines and the process of knowledge creation. Progress in Human Geography, 28(1), 31-56.

Becattini, G. and Bellandi, M. 2006. Distretti industriali: un paradigma socio-economico' in Fortis, M. and Quadrio Curzio, A. (eds), Industria e distretti. Un paradigma di perdurante competitività italiana. Bologna: Il Mulino.

Becattini, G. and Rullani, E. 1996. Local systems and global connections: the role of knowledge. In Cossentino, F., Pyke, F. and Sengenberger, W. (eds), Local and Regional Response to Global Pressure: The Case of Italy and its Industrial Districts. Geneva: International Institute for Labour Studies.

Bellandi, M., De Propris, L. and Santini, E. 2018. Industry 4.0+ Challenges to Local Productive Systems and Place-based Integrated Industrial Policies. Mimeo.

Bellandi, M. and Santini, E. 2019. Territorial servitization and new local productive configurations: the case of the textile industrial district of Prato. Regional Studies, 53(3), 356-365. https://doi.org/10.1080/00343404.2018.1474193.

Bettiol, M., and Micelli, S. 2014. The hidden side of design: the relevance of artisanship. Design/Issues, 30(1), 7-18.

Boschma, R. 2005. Proximity and innovation: a critical assessment. Regional Studies, 39(1), 61-74.

Brusco, S. 1996. Global systems and local systems. In Cossentino, F., Pyke, F. and Sengenberger,W. (eds), Local and Regional Response to Global Pressure: The Case of Italy and its Industrial Districts. Geneva: International Institute for Labour Studies.

Chaminade C., Bellandi M., Plechero, M. and Santini,E., 2017. Paper on the role of RIS/ NIS and knowledge transfer on manufacturing upgrading. MAKERS Deliverable 2.2. Available at: www.makers-rise.org/publications.

Chaminade C., Bellandi M., Plechero, M. and Santini, E. 2018. Path renewal and creation in specialized regional innovation systems. A comparative analysis of two textile districts in Italy and Sweden. Paper presented at the Rethinking Clusters: Critical Issues and New Trajectories of Cluster Research workshop, University of Florence, Italy, 3-4 May.

Cooke, P. and Eriksson, A. 2011. Design-driven regional innovation. In Cooke, P., Asheim, B., Boschma, R., Martin, R., Schwartz, D. and Tödtling, F. (eds), Handbook of Regional Innovation and Growth. Cheltenham: Edward Elgar.

Corradini, C. and De Propris, L. 2015. Technological diversification and new innovators in European regions: evidence from patent data. Environment and Planning A: Economy and Space, 47(10), 2170-2186.

Crespi, G., Fernandez-Arias, E. and Stein, E.H. (eds). 2014. Rethinking Productive Development: Sound Policies and Institutions for Economic Transformation. New York: Palgrave Macmillan.

De Maggio, M., Gloor, P.A. and Passiante, G. 2009. Collaborative innovation networks, virtual communities and geographical clustering. International Journal of Innovation and Regional Development, 1(4), 387-404.

Gertler, M. 2008. Buzz without being there? Communities of practice in context. In Amin, A. and Roberts, J. (eds), Community, Economic Creativity, and Organization, Oxford: Oxford University Press.

Giuliani, E. 2007. The selective nature of knowledge networks in clusters: evidence from the wine industry. Journal of Economic Geography, 7(2), 139-168. 
Grillitsch, M.,Asheim, B.T. and Trippl, M. 2018. Unrelated knowledge combinations: the unexplored potential for regional industrial path development. Cambridge Journal of Regions, Economy and Society, 11(2), 257-274. https://doi.org/10.1093/cjres/rsy012.

Grillitsch, M., Martin, R. and Srholec, M. 2017. Knowledge base combinations and innovation performance in Swedish regions. Economic Geography, 93(5), 458-479.

Grillitsch, M. and Trippl, M. 2014. Combining knowledge from different sources, channels and geographical scales. European Planning Studies, 22(11), 2305-2325.

Herstad, S.J., Aslesen, H.W. and Ebersberger, B. 2014. On industrial knowledge bases, commercial opportunities and global innovation network linkages. Research Policy, 43(3), 495-504.

Isaksen, A. and Trippl, M. 2016. Exogenously led and policy-supported new path development in peripheral regions: analytical and synthetic routes. Economic Geography, 93(5), 436-457.

Jensen, M.B., Johnson, B., Lorenz, E. and Lundvall, B. 2007. Forms of knowledge and modes of innovation. Research Policy, 36(5), 680-693.

Kafouros, M.I., Buckley, P.J. and Clegg,J. 2012.The effects of global knowledge reservoirs on the productivity of multinational enterprises: the role of international depth and breadth. Research Policy, 41(5), 848-861.

Lafuente, E., Vaillant, Y. and Vendrell-Herrero, 2017. Territorial servitization: exploring the virtuous circle connecting knowledge-intensive services and new manufacturing businesses. International Journal of Production Economics, 192, 19-28.

Liu, J., Chaminade, C. and Asheim, B. 2013. The geography and structure of global innovation networks: a knowledge base perspective. European Planning Studies, 21(9), 1456-1473.

Manniche, J., Moodysson, J. and Testa, S. 2017. Combinatorial knowledge bases: an integrative and dynamic approach to innovation studies. Economic Geography, 93(5), 480-499.

Martin, R. 2011. The local geographies of the financial crisis: from the housing bubble to economic recession and beyond. Journal of Economic Geography, 11(4), 587-618.

Martin, R., Aslesen, H.W., Grillitsch, M. and Herstad, S.J. 2018. Regional innovation systems and global flows of knowledge. In Isaksen, A., Martin, R. and Trippl, M. (eds), New Avenues for Regional Innovation Systems: Theoretical Advances, Empirical Cases and Policy Lessons. Cham: Springer.

Martin, R. and Moodysson, J. 2011. Innovation in symbolic industries: the geography and organization of knowledge sourcing. European Planning Studies, 19(7), 1183-1203.

Martin, R. and Moodysson, J. 2013. Comparing knowledge bases: on the geography and organization of knowledge sourcing in the regional innovation system of Scania, Sweden. European Urban and Regional Studies, 20(2),170-187.

Martin, X. and Salomon, R. 2003. Knowledge transfer capacity and its implications for the theory of the multinational corporation. Journal of International Business Studies, 34(4), 356-373.

Mattes, J. 2012. Dimensions of proximity and knowledge bases: innovation between spatial and non-spatial factors. Regional Studies, 46(8),1085-1099.

Morozov, E., and Bria, F. 2018. Rethinking the Smart City: Democratizing Urban Technology. New York: Rosa Luxemburg Stiftung.

OECD. 2016. Science, Technology and Innovation Outlook 2016: Megatrends Affecting Science, Technology and Innovation. Paris: OECD Publishing. 
Perez, C. 2009. Technological revolutions and techno-economic paradigms. Cambridge Journal of Economics, 34(1), 185-202.

Powell, W. 1990. Neither market nor hierarchy. Research in Organizational Behaviour, 12, 295-336.

Rosenkopf, L. and Almeida, P. 2003. Overcoming local search through alliances and mobility. Management Science, 49(6), 751-766.

Rullani, F. and Rullani, E. 2018. Dentro La rivoluzione digitale. Per una nuova cultura dell'impresa e del management. Turin: Giappichelli Editore.

Santini, E. and Bellandi, M. 2017. Paper on the impact of new technology on the 9 organisation of production in high-tech districts or clusters. MAKERS Report. 10. Available at: www.makers-rise.org/wp-content/uploads/2018/03/D3.1-11-Paperon-the-impact-of-new-technology-on-the-organisation-of-production-in-hightech-districts-or-clusters.-Protected.pdf.

Song, J., Almeida, P. and Wu, G. 2003. Learning-by-hiring: when is mobility more likely to facilitate interfirm knowledge transfer? Management Science, 49(4), 351-365.

Storper, 2009. The economics of context, location and trade: another great transformation? In Becattini, G., Bellandi, M. and De Propris, L. (eds), A Handbook of Industrial Districts. Cheltenham: Edward Elgar.

Strambach, S. 2017. Combining knowledge bases in transnational sustainability innovation: microdynamics and institutional change. Economic Geography, 93(5), 500-526.

Strambach, S. and Klement, B. 2012. Cumulative and combinatorial micro-dynamics of knowledge: the role of space and place in knowledge integration. European Planning Studies, 20(11), 1843-1866.

Torre, A. 2008. On the role played by temporary geographical proximity in knowledge transmission. Regional Studies, 42(6), 869-889.

Trippl, M., Grillitsch, M. and Isaksen, A. 2017. Exogenous sources of regional industrial change: attraction and absorption of non-local knowledge for new path development. Progress in Human Geography, 42(5), 687-705.

Trippl, M., Tödtling, F. and Lengauer, L. 2009. Knowledge sourcing beyond buzz and pipelines: evidence from the Vienna software sector. Economic Geography, 85(4), 443-462.

World Bank. 2017. Trouble in the Making? The Future of Manufacturing-Led Development. Washington, DC: World Bank. 